\title{
The Estimation of Hydrometeor Profiles From Wideband Microwave Observations
}

\author{
Gail M. Skofronick-Jackson \\ Universities Space Research Association \\ NASA Goddard Space Flight Center \\ Code 975, Bldg. 33, Room A428 \\ Greenbelt, MD 20771 \\ 301-614-5720, FAX 301-614-5558 \\ gail@sensor2.gsfc.nasa.gov \\ and \\ James R. Wang \\ NASA Goddard Space Flight Center \\ Code 975, Bldg. 33, Room A416 \\ Greenbelt, MD 20771 \\ Accepted by the Journal of Applied Meteorology \\ December 12, 1999
}

\section{Significant Findings}

The estimation of microphysical profiles from anvil, convective and updraft regions of an oceanic tropical squall were presented. The estimation procedure relied on comparisons between brightness temperature calculations and wideband concurrent dual altitude brightness temperature observations. Each of the three estimated cloud profiles produced calculated brightness temperatures within 10 Kelvin of the observations. It was found that a majority of the total iterative adjustments were to the estimated profile's frozen hydrometeor characteristics and were required to match the high frequency calculations with the observations. The major conclusions of this work include the findings that: (1) the microphysical parameters of ice are more detailed and difficult to obtain than are the liquid microphysical parameters, (2) cloud resolving models should be validated using frequencies $>=150 \mathrm{GHz}$, and (3) the estimated profiles explain the variability in the observations and hence give gross clues as to how the upper cloud is structured. In addition, some difficulties matching the $37 \mathrm{GHz}$ observation channels on the DC-8 and ER-2 aircraft with the calculations simulated at the two aircraft heights were noted and potential causes presented. 


\section{Abstract}

Profiles of the microphysical properties of clouds and raincells are essential in many areas of atmospheric research and operational meteorology. In order to enhance the understanding of the nonlinear and underconstrained relationships between cloud and hydrometeor microphysical profiles and passive microwave brightness temperatures, estimations of cloud profiles for an anvil, a convective, and an updraft region of an oceanic squall were performed. The estimations relied on comparisons between radiative transfer calculations of incrementally estimated microphysical profiles and concurrent dual-altitude wideband brightness temperatures from the 22 February 1993 flight during TOGA-COARE.

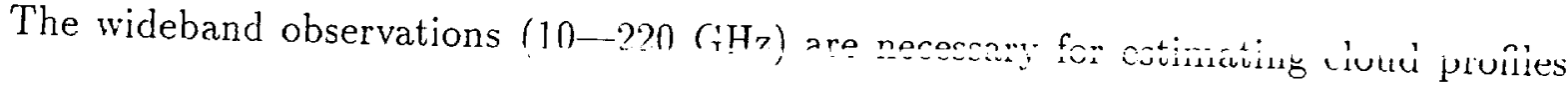
reaching up to $20 \mathrm{~km}$. The low frequencies enhance the rain and cloud water profiles, while the high frequencies are required to detail the higher altitude ice microphysics. A microphysical profile was estimated for each of the three regions of the storm. Each of the three estimated profiles produced calculated brightness temperatures within $\sim 10 \mathrm{~K}$ of the observations. A majority of the total iterative adjustments were to the estimated profile's frozen hydrometeor characteristics and were necessary to match the high frequency calculations with the observations. This indicates a need to validate cloud resolving models using high frequencies. Some difficulties matching the $37 \mathrm{GHz}$ observation channels on the DC-8 and ER-2 aircrafts with the calculations simulated at the two aircraft heights ( $\sim 11 \mathrm{~km}$ and $20 \mathrm{~km}$, respectively) were noted and potential causes presented. 


\title{
The Estimation of Hydrometeor Profiles From Wideband Microwave Observations
}

\author{
Gail M. Skofronick-Jackson \\ Universities Space Research Association \\ NASA Goddard Space Flight Center \\ Code 975, Bldg. 33, Room A428 \\ Greenbelt, MD 20771 \\ 301-614-5720, FAX 301-614-5558 \\ gail@sensor2.gsfc.nasa.gov \\ and \\ James R. Wang \\ NASA Goddard Space Flight Center \\ Code 975, Bldg. 33, Room A416 \\ Greenbelt, MD 20771 \\ Accepted by the Journal of Applied Meteorology \\ December 12, 1999
}

\section{Popular Summary}

Profiles of the microphysical properties of clouds and raincells are essential in many areas of atmospheric research and operational meteorology. In order to enhance the understanding of the nonlinear and underconstrained relationships between cloud and hydrometeor microphysical profiles and passive microwave brightness temperatures, estimations of cloud profiles for an anvil, a convective, and an updraft region of an oceanic squall were performed. The estimations relied on comparisons between radiative transfer calculations of incrementally estimated microphysical profiles and concurrent dual-altitude wideband $(10--220 \mathrm{GHz})$ brightness temperatures observed during TOGACOARE. The low frequencies enhance the rain and cloud water profiles, while the high frequencies are required to detail the higher altitude ice microphysics. Each of the three estimated cloud profiles produced calculated brightness temperatures within 10 Kelvin of the observations. 


\title{
The Estimation of Hydrometeor Profiles \\ From Wideband Microwave Observations
}

\author{
Gail M. Skofronick-Jackson \\ Universities Space Research Association \\ Goddard Visiting Scientist Program \\ Seabrook, Maryland 20706 \\ and \\ Jảmes R. Wang \\ NASA Goddard Space Flight Center \\ Code 975, Bldg. 33, Room A416 \\ Greenbelt, MD 20771
}

Submitted for publication in:

Journal of Applied Meteorology

June 23, 1999

Revised: December 6, 1999

Accepted: December 21, 1999
To be published August 2000 (approximately) 


\section{Introduction}

An understanding of the relationships between passive microwave brightness temperatures $\left(T_{B}\right)$ and the microphysical characteristics of hydrometeors has long been a goal of atmospheric scientists (Wilheit et al. 1982; Smith et al. 1992; Wang et al. 1998). Knowledge of these relationships is essential for many reasons including: developing cloud resolving models (e.g., Tao and Simpson 1993), improving forward radiative transfer calculations (e.g., Smith et al. 1992), computing vertical diabatic heating profiles (e.g., Tao et al. 1993), and in precipitation parameter retrieval algorithms (e.g., Marzano et al. 1999; Smith et al. 1992). In order to gain information about these relationships many theoretical (e.g., Adler et al. 1990; Smith et al. 1992) and experimental (e.g.. Hevmsfield et. al. 1996. Simpson et al. 1996; Liu and Curry 1998) studies have been performed. In general, these studies compare $T_{B}$ observations to $T_{B}$ calculations using estimated microphysical profiles or use empirical knowledge gained from experimental observations. The results from these studies have clarified the relationships between the size distributions of liquid (rain and cloud water) hydrometeors and the upwelling brightness temperatures over oceans. While the liquid hydrometeor relationships are fairly well understood for low frequencies (Wilheit 1986), with only minor differences for varying cloud types, the relationships between the higher altitude frozen hydrometeors in convective clouds and the brightness imagery is less clear.

The relationships between frozen hydrometeors and the $T_{B}$ are more difficult to grasp for several reasons. including inherent nonlinearities, the enormous variety of frozen particle shapes, sizes, and air-ice-water ratios (LaChapelle 1969), the sparsity of measured and/or "true" ice profiles along with coincident, colocated $T_{B}$ observations and the low 
sensitivity of the commonly-used lower frequencies to the frozen hydrometeors. Many theoretical studies have begun to address the nonlinear relationships between the $T_{B}$ and the shapes and sizes of frozen hydrometeors (e.g., Evans and Stephens 1995). In addition, several experimental field campaigns have attempted to coincidently measure both $T_{B}$ 's and cloud microphysical characteristics (e.g., Webster and Lucas 1992; Simpson et al. 1996; McFarquhar and Heymfield 1996) with limited success. Many of these experimental studies use low to mid frequencies $(\leq 90 \mathrm{GHz})$ to investigate and estimate microphysical profiles. However as shown in this paper, many estimated profiles with different ice microphysics can match the $\leq 90 \mathrm{GHz}$ frequency observations.

By using both low and high frequency observations, a more accurate relationshin between the $T_{B}$ and the liquid and frozen hydrometeors can be found. The low frequencies can be used to estimate the low altitude liquid hydrometeors, while the high frequencies are necessary in enhancing the higher altitude ice microphysical details (Evans and Stephens 1995). This paper will describe how coincident wideband $(10-220 \mathrm{GHz})$ passive microwave $T_{B}$ observations from radiometers on both the DC-8 aircraft ( $\sim 11 \mathrm{~km}$ altitude) and the ER-2 aircraft ( $\sim 20 \mathrm{~km}$ altitude) obtained during TOGA-COARE (Tropical Ocean Global Atmosphere/Coupled Ocean Atmosphere Response Experiment) were utilized to investigate the underlying microphysical cloud profiles. A nadir-viewed, dual-altitude comparison between TOGA-COARE brightness temperature observations and computed brightness temperatures was the basis for the microphysical profile estimation procedure. Microphysical profiles used in the calculations were initialized with profiles obtained from the Goddard Cumulus Ensemble (Tao and Simpson 1993) cloud parameterization model. Ice densities and drop size distributions were augmented with densities obtained during experimental observations. By systematically varying the microphysical cloud parameters 
(e.g., particle size distributions and the hydrometeor density) and requiring that the calculations remain consistent with the wideband TOGA-COARE observations, the cloud conditions were estimated for three regions of an oceanic convective storm.

Microphysical profiles for an anvil, convective, and convective updraft region of a storm observed on 22 February 1993 during TOGA-COARE are estimated. While knowledge of the estimated profiles for the three case specific regions reported herein is interesting, this work identifies the advantages of wideband and in particular, high frequency $(\geq 90 \mathrm{GHz}$ ) observations. High frequency observations can clarify high altitude $(\geq 8 \mathrm{~km}$ ) microphysics. Improved knowledge of ice microphysics can then be used to validate and enhance cloud resolving models. Cloud resolving models muct arrount for hoth low and high altitude microphysics in order to accurately represent cloud systems. This work compliments current cloud model verification efforts which focus on low frequency observations and hence low altitude microphysics. Another advantage of a detailed wideband comparison is to validate instrument calibration.

This paper begins by describing the observational data from TOGA-COARE. In particular, the instruments and the three regions of interest for a flight on 22 February 1993 are detailed. The $T_{B}$ calculations and baseline vertical microphysical profiles are described. Then the procedure used to compare the observations with the calculations in estimating the microphysical profiles for the three regions is outlined. The last section summarizes the conclusions. 


\section{Observations}

The brightness temperature observations of interest were obtained early in 1993 during TOGA-COARE. Among the sensors that measured the response to atmospheric hydrometeors in the microwave region of the electromagnetic spectrum during TOGACOARE were the AMPR (Advanced Microwave Precipitation Radiometer) (Spencer et al. 1994), and MIR (Millimeter-wave Imaging Radiometer) (Racette et al. 1996) on board the ER-2 aircraft, and the AR.MAR (Airborne Rain Mapping Radar) (Durden et al. 1994), and AMMR (Airborne Multi-channel Microwave Radiometer) (Wang et al. 1994), and AMMS (Airborne Microwave Moisture Sounder) (Wang and Chang 1990) on board the DC-8. The MIR observation frequencies were $89,150,183.3 \pm 1,183.3 \pm 3.183 .3 \pm 7$. and $220 \mathrm{CH}$. while the AMPR observed at $10 . \overline{7}, 19.3 .5 .3 \pi$, and $55 \mathrm{GHz}$. On the DC-8 aircraft the A.M.MR operated at 18.7, 21, 37, and $92 \mathrm{GHz}$, and the frequencies for the AMMS were $92,183.3 \pm 2$,

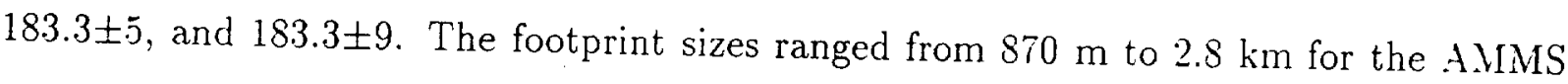
183.3 $\mathrm{GHz}$ channels and the AMPR $10.7 \mathrm{GHz}$ channel, respectively. The ARMAR was a single-channel $13.8 \mathrm{GHz}$ radar.

There were a few coordinated flights where the DC-8 under-flew the ER-2 and provided a rich data set of observed brightness temperatures at 2 altitudes $(\sim 11 \mathrm{~km} \mathrm{DC-8}$ and $\sim 20 \mathrm{~km}$ ER-2). One such coordinated data flight occurred on 22 February 1993. Here the DC-8 flew through an oceanic convective storm and the ER-2 flew over the same latitude and longitude (fairly straight flight track from $9.503^{\circ} \mathrm{S}, 1.58 .577^{\circ} \mathrm{E}$ to $9.503^{\circ} \mathrm{S}$, $159.082^{\circ} \mathrm{E}$ ) just a little over 2 minutes later. This well studied event (e.g., Wang et al. 1998; Jorgensen et al. 1995; Trier et al. 1996; Marzano et al. 1999) was near Guadalcanal Island in the Western Pacific with a north-south oriented squall-line. Figure 1 shows the radar 
reflectivities from the ARMAR for this flight track. The convective system was slanted from right to left with increasing altitude on the left hand side. The freezing level was near $4 \mathrm{~km}$ altitude, however high reflectivity values exist above the freezing level. In the storm core, some radar reflectivities exceed $4.5 \mathrm{~dB}$ or are severely attenuated (green-colored area).

Figure 2 shows the low and mid-frequency $(\leq 90 \mathrm{GHz})$ nadir-viewed $T_{B}$ values for each aircraft, while Fig. 3 shows the high frequency $T_{B}$ values. These figures reinforce the qualitative information obtained from the radar reflectivity plot in Fig. 1. Figure 2 shows evidence of a scattering signature in the $37 \mathrm{GHz}$ channels from about 21:32:40 (UTC DC-8). There is also evidence of scattering at 19 and $21 \mathrm{GHz}$ near 21:34:40 (UTC DC-8) where there is a slight depression in these $T_{R}$ values. For Fig. 3. the left hand tilt and anvil region (arrow $A$ ) of the storm becomes noticeable in the differences between the DC- $\delta$ and ER-2 $T_{B}$ values where there is a $100 \mathrm{~K}$ difference due to ice scattering at the upper altitudes. An area of uniform convection is identified with the $\mathrm{C}$ arrow. Note that the $10.7 \mathrm{GHz}$ channel only reaches a maximum near the convective updraft region (arrow $\mathrm{U}$ ) where there is significant liquid water as indicated by the attenuation from rain in the radar reflectivities (green-colored).

The first region of interest is the anvil region $(21: 33: 14-21: 33: 55$ ER-2 UTC, 21:31:08 - 21:31:49 DC-S UTC, arrow A). This region is characterized by a theorized high ice cloud above the ARMAR field of view. Comparing the DC-8 and ER-2 $183 \mathrm{GHz}$ channels in Fig. 3 (arrow A) shows that the ER-2 $183 \mathrm{GHz}$ channels are about $100 \mathrm{~K}$ lower than the DC-8 $183 \mathrm{GHz}$ channels. These significantly lower $T_{B}$ values along with $90 \mathrm{GHz}$ channels with similar responses (Fig. 3) indicate that frozen hydrometeors at altitudes $\geq 10 \mathrm{~km}$ (an anvil cloud) are effective scatters at frequencies greater than $90 \mathrm{GHz}$. 
The second region of interest is a convective region $(21: 35: 37-21: 35: 48$ ER-2 UTC, 21:33:07 - 21:33:18 DC-8 UTC). This region (arrow C in Figs. 1, 2, 3) is characterized by $45+\mathrm{dB}$ radar reflectivity values from about 2 to $4 \mathrm{~km}$ and fairly significant radar reflectivity returns above the freezing level. The convection is fairly uniform in this region and the $T_{B}$ values show that the $183.3 \mathrm{GHz}$ channels are about $60 \mathrm{~K}$ cooler for the MIR than for the AMMS on the DC- 8 indicating the existence of ice scatters above the DC- 8 aircraft. The warm low frequency $T_{B}$ values (Fig. 2) are due to the presence of liquid (rain and cloud water) absorbers below the freezing level.

The third region (21:37:00 - 21:37:06 ER-2 UTC, 21:34:24 - 21:34:32 DC-8 UTC) is characterized by strong updrafts and high radar reflectivities. This region (arrow U in Figs. 1, 2, 3) is not uniform and shows significant vertical and horizontal variability. The radar reflectivities (Fig. 1) show significant attenuation at low altitudes caused by heavy rainfall. In Fig. 2 the low frequencies are warm indicating the presence of rain, while the high frequency $T_{B}$ values (Fig. 3) are very low suggesting large amounts of ice.

Other experimental data used in this research occurred during the Central Equatorial Pacific Experiment (CEPEX) in March and April of 1993 (McFarquhar and Heymfield 1996). CEPEX sampled frozen hydrometeor number densities and drop size distributions in the same Australian warm pool region as during the TOGA-COARE experiment observed. Liu and Curry analyzed this data and presented profiles of cloud ice average size, average density, and number density ${ }^{1}$ as a function of temperature (Liu and Curry 1998). As will be shown in Section 4 , the CEPEX data is used to enhance the ice

\footnotetext{
${ }^{1}$ Note that the units of $N_{0}$ in Fig. 2 of (Liu and Curry 1998) are incorrectly specified. The correct units are $\mathrm{m}^{-3} \mu \mathrm{m}^{-1}$ (Liu 1997).
} 
microphysics in the estimated profiles.

\section{Brightness Temperature Calculations}

A radiative transfer model is required to transform the (iteratively) estimated microphysical atmospheric profile information into upwelling passive microwave brightness temperatures. The planar-stratified, scattering-based radiative transfer (RT) model used herein was originally developed by Gasiewski and Staelin (1990) and later modified to allow for five (or more) hydrometeor types (e.g., suspended cloud water, rain, suspended cloud ice, snow, graupel) (Skofronick-Jackson and Gasiewski 1995). The radiative transfer model requires as input vertical profiles of temperature, height, relative humidity, and five hydrometeor parameters (per hydrometeor type): type, density ( $\left.\mathrm{g} \mathrm{m}^{-3}\right)$, particle average radius $\left(a_{0}, \mathrm{~mm}\right)$, particle intercept $\left(N_{0}, \mathrm{~mm}^{-1} \mathrm{~m}^{-3}\right)$, and a flag identifying if the particle has a monodisperse or polydisperse size distribution. Flexibility exists in that the user can select observation height, viewing angle, frequency and polarization. In this work a nadir viewing angle is assumed and the observation heights and frequencies match those of the ER-2 and DC-S aircraft instrumentation. Since this work uses nadir $T_{B}$ s observed with a narrow beam width, the plane parallel radiative transfer model is acceptable. In addition, a calm ocean surface with a $27^{\circ} \mathrm{C}$ temperature and with wind speeds $\leq 6 \mathrm{~m} \mathrm{~s}^{-1}$ is assumed. The ocean is obscured for all but the lowest frequencies for all three storm scenarios, thus a calm ocean model is acceptable.

In computing the absorption and scattering coefficients for the individual hydrometeors, decaying exponential polydispersive size distributions are assumed (unless the drop size distribution dictates a monodispersive size distribution). The RT code uses either Rayleigh or Wie theory based on the electrical size of the hydrometeor. When the 
electrical size is small $\left(|n \chi|<0.5\right.$, where $n$ is the complex refractive index and $\chi=\frac{2 \pi r}{\lambda}$ (Ulaby et al. 1981)) the easier-to-implement Rayleigh theory is used. Typically dielectric mixing theory (Borhen and Battan 1980) is used to determine the effective dielectric constant (permittivity, $n^{2}$ ) of the heterogeneous hydrometeors (e.g., snow and graupel). The fractions of entrained ice, air, and water for these particles must be specified along with their drop size distributions. The validity of this (and most) dielectric mixing theories is void when the size of the inclusion is greater than or equal to the wavelength (Borhen and Battan 1980; Sihvola 1989). For a typical mid-latitude oceanic convective storm, validity is ensured to at least $100 \mathrm{GHz}$ (Skofronick-Jackson and Gasiewski 1995). Since this research includes frequencies up to $220 \mathrm{GHz}$, all frozen hydrometeors have been restricted ¿u hutrogeneuus sulid ice so that aieiectric mixing theory is not necded. In addition, a spherical shape is assumed for all hydrometeors.

The estimated microphysical profiles are initially obtained from the Goddard Cumulus Ensemble (GCE) three-dimensional simulated cloud model (Tao and Simpson 1993). The GCE simulation used in this research was initialized using nearby composite aircraft and radiosonde sounding obtained a few hours earlier than the DC-S/ER-2 observations on 22 February 1993. The GCE model produces 4-dimensional distributions of hydrometeors that have been used as input to passive microwave radiative transfer and space-borne precipitation radar models by researchers for improving their precipitation retrievals (e.g., Prasad et al. 199.5; Yeh et al. 1995; Simpson et al. 1996). For the 22 February 1993 GCE cloud model. the assumed size distributions, or number of particles with diameter $D$, follow a decaying inverse exponential drop size distribution:

$$
N_{h}(D)=N_{h_{0}} e^{-\frac{D}{2 a_{h_{0}}}} \mathrm{~m}^{-3} \mathrm{~mm}^{-1}
$$


where (Rutledge and Hobbs 1984)

$$
a_{h 0}=2.0\left[\frac{M_{h}}{\pi \rho_{h} N_{h_{0}}}\right]^{0.25}=\langle r\rangle \mathrm{mm}
$$

In the above, $M_{h}$ is the partial density $\left(\mathrm{g} \mathrm{m}^{-3}\right)$ of hydrometeor $h$ in a cubic meter of air, $\rho_{h}$ is the average intrinsic density $\left(\mathrm{g} \mathrm{m}^{-3}\right)$ of the hydrometeor, $N_{h_{0}}\left(\mathrm{~m}^{-3} \mathrm{~mm}^{-1}\right)$ is the intercept multiplier and $\langle r\rangle$ is the average hydrometeor radius. The partial density $M_{h}$ is provided by the GCE or CEPEX microphysical cloud data. Here $h$ is used to distinguish among the various classes of hydrometeors (e.g., $\rho_{w}, \rho_{r}, \rho_{i}, \rho_{s}$, and $\rho_{g}$ denote the intrinsic density of cloud water, rain, ice, snow, and graupel, respectively). The rain, snow, and graupel hydrometeors have the exponential size distributions of Rutledge and Hobbs (1984) given

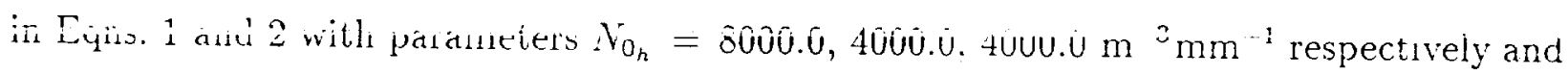
the specific density $\rho_{h}=1.0 \times 10^{9}, 1.0 \times 10^{8}, 4.0 \times 10^{\mathrm{s}} \mathrm{g} \mathrm{m}^{-3}$. respectively. For the referenced GCE case, the ice-air-water ratios for cloud water, rain, cloud ice, snow, and graupel are $0-0-100 \%, 0-0-100 \%, 100-0-0 \%, 10-90-0 \%$, and 40-60-0\% respectively (Tao and Simpson 1993). Note that there is no specified melting layer in the GCE model. The suspended cloud water and ice particles are small enough to advect with the airflow and have a fixed mean diameter of $\left\langle r_{w}\right\rangle=0.003 \mathrm{~mm}$ and $\left\langle r_{i}\right\rangle=0.02 \mathrm{~mm}$. Here, the parameters $N_{u 0}$ and $N_{i 0}$ (and thus the number of particles) vary to account for the differing densities $M_{w}$ and $M_{i}$.

The GCE cloud model is typically used to compare with radar and brightness temperature observations (e.g., Adler et al. 1991; Marzano et al. 1999). The emphasis in these comparisons, however, is based on a general gross scale and on the inherently low altitude rain structures. There were more degrees of freedom when comparisons were made in the regions of mixed-phase and ice clouds at higher altitudes. Since the scattering 
coefficient in the Rayleigh region goes as (Borhen and Huffman 1983)

$$
\sim N_{0} f^{4} r^{6}
$$

(where $f$ is the frequency), the size $(r)$ of the particle dominates the scattering term. Thus small changes in $r$ can lead to significant changes in the brightness temperature. In the Mie region, the relationships are less clear, however, particle size is still extremely important. In general, the GCE modeled particles do not reproduce the high frequency brightness temperatures observed by the airborne radiometers for the three regions of interest from the 22 February 1993 TOGA-COARE flights. This suggests the need of adjusting the model-produced cloud microphysics and possibly modifying the parameters in the initialization of the GCE model.

In order to adjust the GCE produced microphysical profiles and to provide additional hydrometeor types, two other drop size distributions were included in the radiative transfer code. The CEPEX data, as analyzed by Liu and Curry (1998), was incorporated into the code. However because the CEPEX data is derived from measurements (McFarquhar and Heymfield 1996) there is not a realistic method for varying the density, or drop size in order to vary the microphysical profile and thus the calculated $T_{B}$. In order to provide more flexibility in the frozen hydrometeor drop size distributions, the Sekhon and Srivastava (1970) drop size distribution was also included. Generally the CEPEX density was used in the Sekhon-Srivastava (SS) drop size distribution equations which follow Eqs. 1 and 2 with

$$
a_{0}=0.422 M^{0.52} \mathrm{~mm}
$$

and

$$
N_{0}=636.4 M^{-1.09} \mathrm{~mm}^{-1} \mathrm{~m}^{-3} .
$$


Because the SS drop size distribution is of a functional form, changes in $M, a_{0}$, or $N_{0}$ can be applied and propagated through to the absorption and scattering coefficient calculations. Changes in $M$ or $a_{0}$ were often necessary because the CEPEX data was an average of the measured microphysics and the cases studied in this work were at the extreme ends of convective and anvil cloud structures. A comparison between the CEPEX drop size distribution and the SS drop size distribution shows that for a fixed density $M$, the SS average radius is smaller and $N_{0}$ is larger than for the CEPEX case.

\section{Estimations}

A wideband, nadir-viewed, dual-altitude comparison between TOGA-COARE brightness temperature $\left(T_{B}\right)$ observations and computed brightness temperatures was the basis for the estimation procedure. A feedback procedure in the comparison process is used to iteratively improve the estimated microphysical profiles. The feedback procedure, driven by an understanding of hydrometeor $-T_{B}$ relationships, adjusts the microphysical parameterizations of hydrometeor density, drop size distribution, and the ice-air-water fractions of the frozen hydrometeors. In order to obtain the best retrieved profile, changes in the hydrometeor parameterizations were not constrained to conserve the physical parameters (e.g., mass) of the initializing profile. By varying the microphysical cloud parameters (e.g., particle size distributions and the hydrometeor density) and requiring that the comparisons remain consistent with the wideband TOGA-COARE brightness temperature observations, the cloud conditions between the two aircraft were estimated. Concurrent radar reflectivities from the ARMAR on the DC-S are also used in the analysis to provide a crude profile of rain densities when the GCE data was inadequate.

The feedback/iterative process is stopped when at least fifteen out of sixteen 
observed microwave channels of the ER-2 and DC- 8 are within $\pm 10 \mathrm{~K}$ of the calculated $T_{B}$ values. While not adopted in this work, the $\pm 10 \mathrm{~K}$ requirement could be lessened for channels with larger footprint sizes due to the microphysical information lost during the observation process. Furthermore, the RMS error of the calculated minus observed differences was minimized. While the estimated profiles do match the $T_{B}$ observations fairly well, there is no guarantee that these profiles are the global minimum in the solution space. While the retrieved profiles may not be unique, variations of the profiles would only affect the RMS error. The conclusions are not expected to change. Furthermore the estimated profiles do explain the variability in the observations and hence give gross clues as to how the upper cloud is structured.

\section{(a) Anvil Region}

For the anvil case, the $128 \times 128$ profiles of the most mature time frame $(360$ minutes) of the three-dimensional GCE microphysical cloud were sorted to determine which profiles contained large amounts of frozen hydrometeors at higher altitudes $(\geq 11 \mathrm{~km})$. Eight favorable vertical profiles were selected and extracted for use as baseline microphysical profiles. Each of the eight profiles were non-precipitating with frozen hydrometeor densities exceeding $2 \mathrm{~g} \mathrm{~m}^{-3}$ above $11 \mathrm{~km}$. (These were the maximum upper altitude ice densities in the available GCE profiles.) Using the drop size distributions suggested in Tao and Simpson (1993) and described in Section 3 the brightness temperatures were computed for the eight profiles. The brightness temperatures were averaged together to compare with averaged brightness temperatures from the specified anvil region $\mathrm{UTC}$ times of the ER-2 and DC-S (arrow $A$ in Figs. 1, 2, 3).

The resultant averaged brightness temperatures are provided in Table 1. In 
comparing these values with the observations, all calculated values for frequencies $\geq 150 \mathrm{GHz}$ are too warm by up to $80 \mathrm{~K}$ with respect to the ER-2 observations at those frequencies. On the other hand, the high frequency DC- 8 altitude calculations are cooler than the DC- 8 observations. In fact, the calculated $T_{B}$ values are too cool by $10-50 \mathrm{~K}$ for all the DC-S observed frequencies. These comparisons indicate several items about the calculations: (1) there is not enough small-sized ice at the higher ( $\geq 11 \mathrm{~km}$ ) altitudes, (2) that the ice-air mixtures in the snow and graupel do not produce enough scattering, (3) that dielectric mixing theories used for the GCE snow and graupel may be breaking down at the highest frequencies, or (4) there may be too much ice, or incorrectly-sized ice at the lower altitudes.

In attempting to correct for the inconsistencies described above, the frozen hydrometeor components of the GC'E profile were replaced by averaged ice densities and drop size distributions as derived by Liu and Curry (1998) using the CEPEX data. The selected GCE profiles were modified such that all the cloud ice, snow, and graupel were replaced with the CEPEX densities and drop size distributions whenever $T \leq 273.15 \mathrm{~K}$, (i.e., at heights $\geq \sim 5 \mathrm{~km}$ ). The resultant $T_{B}$ values are provided in Table 1 . This table shows that while the ER-2 simulated calculations are closer to the observations, the DC-8 calculations are in worse agreement with the observations. These unfavorable comparisons indicate that the CEPEX densities and drop size distributions will require further adjustment prior to obtaining a favorable comparison.

After evaluating many ice density and drop size distributions through a manual feedback analysis, the best microphysical parameterization used a hybrid profile (Fig. 4) combining the GCE profile, CEPEX ice. and variations of the Sekhon and Srivastava (1970) 
drop size distribution. The calm ocean surface temperature was assumed to be $301 \mathrm{~K}$ and the relative humidity varied from $73 \%$ to $100 \%$. In the hybrid profile, the GCE cloud water densities were replaced with the GCE rain water densities (which were small to start with) and the rain densities zeroed. Because the cloud water is monodisperse with a fixed drop diameter of $0.015 \mathrm{~mm}$, less absorptive warming occurs and the $18-89 \mathrm{GHz}$ calculations match better with the observations. With the zeroed rain densities, the calculated $10.7 \mathrm{GHz}$ channel was still too cool, thus the cloud water densities below $250 \mathrm{~m}$ were multiplied by 4.0 to add absorptive warming to the $10.7 \mathrm{GHz}$ channel. The frozen hydrometeors started at an altitude of $8 \mathrm{~km}\left(-15^{\circ} \mathrm{C}\right)$ where the CEPEX ice densities were used with the SS drop size distribution up to an altitude of $16 \mathrm{~km}$. Starting the ice at a higher altitude than thic fieceing level ( $\sim \mathrm{jm}$ ) is more appropriate given the low return in the low altitude radar reflectivities of Fig. 1 and the too cool DC-S $T_{B}$ calculations of Table 1 . From 12 to $14 \mathrm{~km}$, the CEPEX ice densities using the CEPEX drop size distribution is added to increase the scattering component thus reducing the high-altitude high-frequency brightness temperatures.

The resultant brightness temperatures for the modified drop size distributions are provided in Table 1. In comparing these with the observations on 22 February 1993 from 21:33:14 - 21:33:49 UTC (ER-2), the results are favorable. All $T_{B}$ values are within $\pm 10 \mathrm{~K}$ of the observations. The average error (absolute value of the differences) of the hybrid profile is $4.5 \mathrm{~K}$, while the R.MS error of the differences is $1.3 \mathrm{~K}$.

\section{(b) Convective Region}

For the convective case, the GCE data was used to provide a baseline profile of height, temperature, relative humidity, and cloud water density. The GCE data was not 
used to provide profiles of frozen hydrometeor densities due to dielectric mixing issues associated with the GCE inhomogeneous snow and graupel hydrometeors. In addition, instead of sorting through the $128 \times 128 \mathrm{GCE}$ pixels for a suitable rain profile, a crude baseline rain water density was determined using the reflectivity profiles from the ARMAR (arrow C in Fig. 1). Initially, no frozen hydrometeors were present-they were added during the feedback procedure. The relative humidity of the GCE profile was reset to $100 \%$ whenever hydrometeors were present in the profile.

In order to obtain matching computed $T_{B}$ values, several modifications to the baseline profile were necessary. First the rain water required adjustment so that the low frequency calculations better matched the observations. The adjustment increased the rain density by $10 \%$ below the freezing level $(\sim 5 \mathrm{~km})$ and decreased the rain density by $20 \%$ above the freezing level (Fig. 5). This adjustment brought the calculations for $\leq 19.35 \mathrm{GHz}$ to within $8 \mathrm{~K}$ of the $T_{B}$ observations. Since no frozen hydrometeors were initially present, the next step was to add frozen hydrometeors to the lower levels $\left(0^{\circ} \mathrm{C}\right.$ to $\left.\sim 11 \mathrm{~km}\right)$ in order to get the high-frequency low-altitude calculations to match the DC-S high frequency observations. To achieve a better representation, the CEPEX ice densities with a modified SS drop size distribution were added above $6 \mathrm{~km}$. The SS drop size distribution was modified by multiplying the average radius by 1.475 in order to increase the scattering component. In performing the drop size distribution modification, the number density was kept at the original SS value given in Eq. 5. Thus the actual density was modified from the CEPEX density by:

$$
M_{\text {neu }}=M_{C E P E X} C^{4}
$$

where $C$ is the constant multiplied by $a_{0}$ (e.g., 1.475). Above the height of the DC- 8 frozen hydrometeors with a smaller average radius were required to obtain a good match with 
the ER-2 high frequency observations. Thus above $11.3 \mathrm{~km}$ the average SS drop radius as generated from the CEPEX density was divided by 1.5. These small-sized hydrometeors were added to a height of $16 \mathrm{~km}$. In addition, to increase the scattering component, CEPEX densities using the CEPEX drop size distribution was included from 11.3 to $15 \mathrm{~km}$ (Fig. 5). A final adjustment to change the relative humidity to $100 \%$ whenever hydrometeors were present further improved the water vapor channels.

These modifications to the original profile brought 15 of the $16 T_{B}$ calculations to within $10 \mathrm{~K}$ (Table 2) for all observations (arrow $\mathrm{C}$ in Figs. 1, 2, 3). Potential causes for the mismatched ER-2 $37 \mathrm{GHz}$ channel are provided in Appendix A. The average absolute value difference between the observations and calculations is $4.273 \mathrm{~K}$ while the RMS error is $5.58 \mathrm{~K} \mathrm{~K}$.

\section{(c) Convective Updraft Region}

The radar reflectivity profiles associated with the convective updraft region (Fig. 1 arrow $\mathrm{C}^{*}$ ) indicate strong updrafts lifting rain and ice to altitudes greater than $9 \mathrm{~km}$. There is no clearly defined melting layer, however low altitude attenuation implies heavy rainfall. Thus in defining the baseline profile, the radar reflectivity profile was used to obtain a profile of rain densities. The temperature, height, and cloud water profiles were extracted from a single GCE pixel with convective characteristics. The relative humidity was set equal to $100 \%$ whenever hydrometeors were present.

Since our simple radar reflectivity to rain density conversion did not account for attenuation, additional rain water was required to warm the low frequency channels. Because of the updraft nature of this region the rain water extended above the freezing 
level to approximately $9 \mathrm{~km}$ (Fig. 6). This brought the low frequency channels to within $7 \mathrm{~K}$ of the radiometer observations on both the ER-2 and DC-8 aircraft (Table 3 ).

The next goal was to obtain a match to the DC- 8 observations sensitive to the frozen hydrometeors. Initially the CEPEX ice densities and drop size distributions were used for the frozen hydrometeors. The brightness temperatures resulting from the addition of the CEPEX ice were too warm by an average of $19 \mathrm{~K}$ at 37 and $92 \mathrm{GHz}$ and too cool by an average of $15 \mathrm{~K}$ for the $183.3 \mathrm{GHz}$ channels. These unmatched brightness temperatures imply that there is not enough scattering at the altitudes where the 37 and $92 \mathrm{GHz}$ channels are sensitive, while scattering is too intense for the $183.3 \mathrm{GHz}$ channels. Thus several modifications were made to the microphysical profile.

First to correct for the warm 37 and $92 \mathrm{GHz}$ calculations, we note that Gasiewski (1993) shows that as hydrometeor density increases (over a uniform rain cell) the temperature weighting functions peak at increasing altitudes. Thus for this hydrometeor rich convective updraft region we increased the scattering component at altitudes high for the DC-8, e.g., from $8.25-11 \mathrm{~km}$. In this range, the CEPEX density was multiplied by 11.75 and the SS drop size distribution was used (See Fig. 6). The ice below $8.2 .5 \mathrm{~km}$ was left with the CEPEX drop size distribution. This change brought all the calculated DC-8 altitude brightness temperatures to within $9 \mathrm{~K}$ of their corresponding observations. The low altitude $183.3 \mathrm{GHz} T_{B}$ calculations are warmed because the heavy ice layer between 8.25 and $11 \mathrm{~km}$ provides opacity such that these channels do not probe as deep into the frozen hydrometeor layers. Furthermore, the relative humidity of the profile was increased to $100 \%$ whenever hydrometeors were present.

The final step in the estimation procedure was to cool the high altitude (ER-2) 
high frequency $T_{B}$ calculations by adding ice to the upper altitudes. The microphysical profile below $11 \mathrm{~km}$ was retained in order to preserve the DC- $8 T_{B}$ calculations. Above $11 \mathrm{~km}$ the CEPEX density using the CEPEX drop size distribution was used to the top of the CEPEX cloud top (at $15 \mathrm{~km}$ ). CEPEX ice alone did not provide enough cooling. Therefore a second ice layer was added where the CEPEX density profile was multiplied by 0.25 and used in the SS drop size distribution from 11-16 km (See Fig. 6). These modifications to the upper altitude ice brought all but the ER-2 $37 \mathrm{GHz}$ channel to within $9 \mathrm{~K}$ of the observations (See Table 3). Several causes for difficulties at $37 \mathrm{GHz}$ are noted in Appendix A.

\section{Conclusions}

The estimation of microphysical profiles from anvil, convective and updraft regions of an oceanic tropical squall have been presented. The estimation procedure relied on comparisons between $T_{B}$ calculations and wideband concurrent dual altitude brightness temperature observations. There are several major conclusions of this work: (1) the microphysical parameters of ice are more detailed and difficult to obtain than are the liquid microphysical parameters, (2) cloud resolving models should be validated using frequencies $\geq 150 \mathrm{GHz}$, and (3) the estimated profiles explain the variability in the observations and hence give gross clues as to how the upper cloud is structured. To support these conclusions, the calculations initially assumed hydrometeor microphysics as given in a widely-accepted cloud resolving model. In all three regions of the storm, the cloud model microphysics required substantial modification in order to obtain an acceptable match with the observations. It was found that low frequency ( $<37 \mathrm{GHz}$ ) matching was easily accomplished with minor rariations in the liquid hydrometeor densities and 
drop size distributions. However, for frequencies $\geq 150 \mathrm{GHz}$ the brightness temperature observations required detailed frozen hydrometeor microphysics and approximately $80 \%$ of the feedback iterations were devoted to achieving $T_{B}$ calculations that matched the high frequency observations. We found that the more complex the vertical profile, the more difficult it was to minimize the RMS error and to obtain less than $10 \mathrm{~K}$ calculation minus observation differences. Due to the significant effort needed to obtain a match to the higher frequencies, and the fact that multiple ice microphysical profiles generated $T_{B}$ s that matched observations $\leq 90 \mathrm{GHz}$, cloud resolving models should be validated with observations at frequencies $\geq 150 \mathrm{GHz}$.

This work also showed that the three storm scenarios required very different . ice microphysics in order to produce $T_{B}$ calculations matching the TOGA-COARE observations. By comparing Figs. 4-6, it can be seen that the maximum ice density. $\left(0.07 \mathrm{~g} \mathrm{~m}^{-3}\right)$ and average drop size $(0.11 \mathrm{~mm})$ in the anvil profile are much smaller than for the convective and updraft cases. For the convective and updraft cases, the maximum ice density in the profile is nearly equivalent at 0.51 and $0.48 \mathrm{~g} \mathrm{~m}^{-3}$, respectively. However. the average ice particle sizes for the updraft profile are double those of the convective case. Since the radiative transfer model extends the polydispersive exponential drop sizes to 11 times the average size (Gasiewski 1993), the maximum drop radii are $1.2,2.1$, and $4.0 \mathrm{~mm}$ for the anvil, convective, and updraft regions, respectively.

While this paper presents an improvement in estimating high altitude ice microphysics by using high frequency information, there are at least two approaches that can be used in the next generation of this estimation. First, quantitatively incorporating radar reflectivity observations from the ARMAR and or EDOP would further improve the 
microphysical profile retrievals. In fact, Meneghini et al. (1997) and Marzano et al. (1999) have already started this type of comparison. In addition to make the microphysical profiles more realistic, a layer of inhomogeneous ice particles (a melting layer) should be added. However such a melting layer must be mindful of the frequency-inclusion size limitations associated with the dielectric mixing theories. Thus the size of the inclusions must be very small and/or the melting layer placed at an altitude where the high frequencies do not probe.

\section{Appendix A: Difficulties at $37 \mathrm{GHz}$}

With respect to the difficulties in matching the $37 \mathrm{GHz}$ channels, we note that for both convective and convective updraft regions the observed $T_{B}$ for the ER-2 is warmer than the DC-3 $T_{B}$ values at $37 \mathrm{CH}$. Narmer ER-2 $T_{B}$ values are not seen in the anvil region. There are a few factors that may contribute to these difficulties. These factors are of three types: (1) temporal flight displacement issues, (2) modeling problerns, and (3) estimation algorithm effects. These factors are discussed in this appendix, however, all of these causes are difficult to rerify and suggest the complexity of studying the storm structure in detail.

First the 2-3 minute temporal displacement in the observations over the same locations between the ER-2 and DC-S aircraft could present problems in these comparisons because of the fast moving and changing convective core structure. A close examination of the AMPR image in the neighborhood of the convective updraft region shows that a cold cell with $37 \mathrm{GHz} T_{B}$ values of $\sim 22.5 \mathrm{~K}$ appears about $2 \mathrm{~km}$ upstream and a couple of pixels from nadir. This could be the same cell observed by AMMR on board the DC- 8 aircraft; a positive identification is not possible because AMMR is not an imager. On the other hand, 
the anvil region is expansive and characterized by a gradual and slow change in $T_{B}$, and is therefore unlikely to be subject to the same difficulty.

Next, reproducing the effects of the microphysical parameterization model in the radiative transfer model can be difficult at $37 \mathrm{GHz}$. The $37 \mathrm{GHz}$ channel is much more sensitive to the ratio of frozen to liquid hydrometeors because it responds to both the liquid and frozen hydrometeors fairly equally (whereas, $19 \mathrm{GHz}$ responds mostly to liquid and only slightly to frozen hydrometeors and $89 \mathrm{GHz}$ responds more to ice than liquid). This may mean that our retrieved profile still does not have the proper ratio of frozen to liquid hydrometeors (above the DC- 8 altitude as this is where the $37 \mathrm{GHz}$ calculations are too cool) or that the ratio of frozen versus liquid hydrometeors has changed in the 2-3 minute delay between the DC-S and ER-2 flights. In addition, all frozen hydrometeors have been parameterized as solid ice spheres. In reality, it is likely that in the convective and updraft regions the ice will be an inhomogeneous mixture of ice, air, and water. Adding a melting layer with inhomogeneous ice would warm the low and mid-frequency $T_{B}$ calculations due to the increased absorption component. A concern with adding a melting layer is that the dielectric mixing theories needed to compute the absorption and scattering coefficient require the size of inclusion to be much smaller than the wavelength. This will not be the case for the higher frequencies. In fact, initial tests show almost a $1 \mathrm{~K}$ change in $T_{B}$ for $\geq 150 \mathrm{GHz}$ and more change for lower frequencies when the ice between 0 and $-7^{\circ} \mathrm{C}$ contains $10 \%$ liquid water.

A third factor is that the estimated microphysical profile may only be a local minimum in the solution space and other microphysical profiles might be more appropriate. Finally, the AMMR measurement accuracy is about $\pm 4 \mathrm{~K}$ (Wang et al. 1994). It is quite 
possible that the AMPR calibration accuracy is of the same order of magnitude and thus a measurement discrepancy of $\sim 5-6 \mathrm{~K}$ between these instruments is not totally unexpected. If there are measurement discrepancies for the $37 \mathrm{GHz}$ channels, the estimation algorithm should reduce the $\pm 10 \mathrm{~K}$ requirement for $37 \mathrm{GHz}$.

Acknowledgments-We thank Dr. Ramesh Kakar, manager of TRMM program at NASA headquarters (grant NAS5-7777). This work has also been supported by USRA grant NAS5-32484. The authors thank Dr. W.-K. Tao and S. Lang of the NASA/Goddard Space Flight Center for providing the Goddard Cumulus Ensemble (GCE) three-dimensional microphysical cloud data and Drs. G. Liu and J. A. Curry for the CEPEX data. Finally we thank our reviewers, Drs. Roy Spencer, Joseph Turk, and an anonymous reviewer for constructive comments that have enriched this paper. 


\section{)References .}

Adler, R. F., R. A. Mack, N. Prasad, H.-Y. M. Yeh and I. M. Hakkarinen, 1990: Aircraft microwave observations and simulations of deep convection from 18 to $183 \mathrm{GHz}$. Part I: Observations. J. Atmos. Oceanic Technol., 7, 377-391.

Adler, R. F., H.-Y. M. Yeh, N. Prasad, W.-K. Tao and J. Simpson, 1991: Microwave simulations of a tropical rainfall system with a three dimensional cloud model. J. Appl. Meteor., 30, 924-953.

Borhen, C. F. and L. J. Battan, 1980: Radar backscattering by inhomogeneous precipitation particles. J. Atmos. Sci., 37, 1821-1827.

Borhen, C. F. and D. R. Huffman, 1983: Absorption and Scattering of Light by Small Particles. John Wiley and Sons, New York.

Durden, S. L., E. Im, F. K. Li, W. Ricketts, A. Tanner and W. Wilson, 1994: ARMAR: An airborne rain-mapping radar. J. Atmos. Oceanic Technol, 11, 727-737.

Evans, K. F. and G. L. Stephens, 199.5: Microwave radiative transfer through clouds composed of realistically shaped ice crystals. Part II: Remote sensing of ice clouds. $J$. Atmos. Sci., 52, 2058-2072.

Gasiewski, A. J., 1993: Microwave radiative transfer in hydrometeors. in M. A. Janssen, editor, Atmospheric Remote Sensing by Microwave Radiometry. pp. 91-144. John Wiley and Sons, New York.

Gasiewski, A. J. and D. H. Staelin, 1990: Numerical modeling of passive microwave $\mathrm{O}_{2}$ observations over precipitation. Radio Sci., 25, 217-235. 
Heymsfield, G. M., I. J. Caylor, J. M. Shepherd, W. S. Olson, S. W. Bidwell, W. C. Boncyk and S. Ameen, 1996: Structure of florida thunderstorms using high-altitude aircraft radiometer and radar observations. J. Appl. Meteor., 35, 1736-1762.

Jorgensen, D. P., T. J. Matejka and M. A. LeMone, 1995: Structure and momentum fluxes within a TOGA/COARE squall line system observed by airborne doppler radar. in 21st Conf. Hurricanes and Tropical Meteorology, pp. 579-581, Miami, FL. American Meteorological Society.

LaChapelle, E. R., 1969: Field Guide to Snow Crystals. University of Washington Press, Seattle and London.

Liu, G., iygi. Yersonal Communication, University of Colorado. Bonlder. CO.

Liu, G. and J. A. Curry, 1998: Remote sensing of ice water characteristics in tropical clouds using aircraft microwave measurements. J. Appl. Meteor., 37, 3.37-3.5.5.

Marzano, F. S., A. Mugnai. G. Panegrossi, N. Pierdicca, E. A. Smith and J. Turk. 1999: Beyesian estimation of precipitating cloud parameters from combined measurements of spaceborne microwave radiometer and radar. IEEE Trans. Geosci. Remote Sens., 37 , $596-613$.

McFarquhar, G. M. and A. J. Heymfield, 1996: Microphysical characteristics of three cirrus anvils sampled during the Central Equatorial Pacific Experiment (CEPEX). J. Atmos. Sci., 53, 2424-2451.

Meneghini, R., H. Kumagai, J. R. Wang, T. Iguchi, and T. Kozu, 1997: Microphysical retrievals over stratiform rain using measurements from an airborne dual-wavelength radar-radiometer. IEEE Trans. Geosci. Remote Sens., 35, 4\$ٓ-.506. 
Prasad, N., H.-Y. M. Yeh. R. F. Adler and W.-K. Tao, 1995: Infrared and microwave simulations of an intense convective system and comparison with aircraft observations. $J$. Appl. Meteor., 34, 153-174.

Racette, P., R. F. Adler, J. R. Wang, A. J. Gasiewski, D. M. Jackson and D. S. Zacharias, 1996: An airborne millimeter-wave imaging radiometer for cloud, precipitation and atmospheric water vapor studies. J. Atmos. Oceanic Technol., 13, 610-619.

Rutledge, S. A. and P. Hobbs, 1984: The mesoscale and microscale structure and organization of clouds and precipitation in midlatitude cyclones. XII: A diagnostic modeling study of precipitation development in narrow cold-frontal rainbands. J. Atmos. Sci., 41, 2949-2972.

Sekhon, R. S. and R. Srivastava, 1970: Snow size spectra and radar reflectivity. J. Atmos. Sci., 27, 299-307.

Sihvola, A. H., 1989: Self-consistency aspects of dielectric mixing theories. IEEE Trans. Geosci. Remote Sens. 27. 403-415.

Simpson, J., C. Kummerow. W.-K. Tao and R. F. Adler, 1996: On the tropical rainfall measuring mission (TR.M.M). Meteor. Atmos. Phys., 60, 19-36.

Skofronick-Jackson, G. M. and A. J. Gasiewski, 1995: Nonlinear statistical retrievals of ice content and rain rate from passive microwave observations of a simulated convective storm. IEEE Trans. Geosci. Remote Sens., 33(4), 957-970.

Smith, E. A., A. Mugnai, H. J. Cooper, G. J. Tripoli and X. Xiang. 1992: Foundations for statistical-physical precipitation retrieval from passive microwave satellite measurements. 
Part I: Brightness temperature properties of a time-dependent cloud-radiation model. $J$. Appl. Meteor., 31, 506-531.

Spencer, R. W., R. E. Hood, F. J. LaFontaine, E. A. Smith, R. Platt, J. Gagliano, V. L. Griffin and E. Lobl, 1994: High-resolution imaging of rain systems with the advanced microwave precipitation radiometer. J. Atmos. Oceanic Technol., 11, 849-857.

Tao, W.-K., S. Lang, J. Simpson and R. Adler, 1993: Retrieval algorithms for estimating the vertical profiles of latent heat release: Their applications for TRMM. J. Meteor. Soc. Japan, 71, 685-700.

Tao, W.-K. and J. Simpson, 1993: Goddard cumulus ensemble model. Part I: Model description. Terrestrial. Atmos. and Oceanic Sciences, 4. 35-72.

Trier. S. B., W. C. Skamarock, M. A. LeMone, D. B. Parsons and D. P. Jorgensen, 1996: Structure and evolution of the 22 February TOGA-COARE squall line: Numerical simulations. J. Atmos. Sci., 53(20), 2861-2886.

Ulaby. F. T.. R. K. Moore and A. F. Fung, 1981: Microwave Remote Sensing Active and Passive. Vol. 1. Addison-Wesley Publishing Company, Reading. Massachusetts.

Wang. J. R. and L. A. Chang, 1990: Retrieval of water vapor profiles from microwave radiometric measurements near 90 and $183 \mathrm{GHz}$. J. Appl. Meteor., 29(10), 1005-1013.

Wang. J. R., R. Meneghini. H. Kumagai, T. T. Wilheit, W. C. Boncyk. P. Racette, J. Tesmer and B. Maves. 1994: Active and passive microwave observations of super typhoon Flo. IEEE Trans. Geosci. Remote Sens., GE-32(2), 231-242.

Wang. J. R., J. Zhan and P. Racette, 1998: Multiple aircraft microwave observations of storms over the western Pacific ocean. Radio Sci., 33, 351-368. 
Webster, P. J. and R. Lucas, 1992: TOGA-COARE: The coupled ocean-atmosphere response experiment. Bull. Amer. Meteor. Soc., 16, 1377-1416.

Wilheit, T. T., 1986: Some comments on passive microwave measurement of rain. Bull. Amer. Meteor. Soc., 67, 1226-1232.

Wilheit, T. T., A. T. C. Chang, J. L. King, E. B. Rodgers, R. A. Nieman, B. M. Krupp, A. S. Milman, J. S. Stratigos and H. Siddalingaiahi, 1982: Microwave radiometric observations near $19.35,92$, and $183 \mathrm{GHz}$ of precipitation in tropical storm Cora. J. Appl. Meteor., 21, 1137-1145.

Yeh, H.-Y. M., N. Prasad, R. Meneghini, W.-K. Tao, J. A. Jones and R. F. Adler, 1995: Cloud model-based simulation of spaceborne radar observations. J. Appl. Mettor.. 34. $175-197$. 
Figure 1: The ARMAR $(13.8 \mathrm{GHz})$ radar reflectivity profiles for 22 February 1993 . The ARMAR was on the DC-8 and measured reflectivities to $9 \mathrm{~km}$. The UTC times are of the DC-8 flight.

Figure 2: The low frequency brightness temperature values for 22 February 1993 as observed from the (a) ER-2 and (b) DC-8. The UTC times are of the ER-2 (a) and DC-8 (b) flights.

Figure 3: The high frequency brightness temperature values for 22 February 1993 as observed from the (a) ER-2 and (b) DC-8. The UTC times are of the ER-2 (a) and DC-8 (b) flights.

Figure 4: The estimated profile for the anvil region: (a) densitics, (b) arciagc radii. The rain density equals zero.

Figure 5: The estimated profile for the convective region: (a) densities, (b) average radii.

Figure 6: The estimated profile for the convective updraft region: (a) densities, (b) average radii. 
Table 1: Anvil $T_{B}$ Comparisons

\begin{tabular}{|c|c|c|c|c|c|c|}
\hline aircraft & $\begin{array}{c}\text { frequency } \\
(\mathrm{GHz})\end{array}$ & Observations & \multicolumn{3}{|c|}{$T_{B}$ Calculations } & difference \\
& $(\mathrm{K})$ & GCE & CEPEX Ice & Hybrid & $(\mathrm{K})$ \\
\hline DC-8 & 18.7 & 179.801 & 174.199 & 174.555 & 172.972 & -6.829 \\
DC-8 & 21.0 & 215.756 & 213.359 & 213.526 & 213.211 & -2.545 \\
DC-8 & 37.0 & 209.150 & 218.658 & 216.321 & 215.162 & 6.012 \\
DC-8 & 92.0 & 268.5 .50 & 231.295 & 187.903 & 273.262 & 4.712 \\
DC-8 & $183.3 \pm 2$ & 246.462 & 233.634 & 197.060 & 248.350 & 1.888 \\
DC-8 & $183.3 \pm 5$ & 250.238 & 226.310 & 173.247 & 251.671 & 1.433 \\
DC-8 & $183.3 \pm 9$ & 250.387 & 221.760 & 163.563 & 254.562 & 4.175 \\
\hline ER-2 & 10.7 & 140.340 & 129.880 & 130.029 & 131.251 & -9.089 \\
ER-2 & 19.35 & 179.333 & 183.630 & 18.3 .13 & 1.83 .60 .2 & 1.250 \\
ER-2 & 37.0 & 206.867 & 218.513 & 215.598 & 216.810 & 9.943 \\
ER-2 & 89.0 & 244.860 & 218.489 & 174.18 .5 & 238.41 .5 & -6.445 \\
ER-2 & 150.0 & 175.307 & 203.964 & 154.235 & 176.263 & 0.956 \\
ER-2 & $183.3 \pm 1$ & 154.040 & 218.621 & 175.137 & 150.772 & -3.268 \\
ER-2 & $183.3 \pm 3$ & 148.413 & 213.006 & 165.586 & 148.638 & 0.225 \\
ER-2 & $183.3 \pm 7$ & 147.427 & 208.0 .50 & 160.790 & 149.411 & 1.984 \\
ER-2 & 220.0 & 125.133 & 206.973 & 168.116 & 133.342 & 8.209 \\
\hline
\end{tabular}


Table 2: Convective $T_{B}$ Comparisons

\begin{tabular}{|c|c|c|c|c|}
\hline aircraft & $\begin{array}{c}\text { frequency } \\
(\mathrm{GHz})\end{array}$ & $\begin{array}{c}\text { TOGA-COARE } \\
\text { Observations }\end{array}$ & $\begin{array}{c}T_{B} \\
\text { Calculations }\end{array}$ & $\begin{array}{c}\text { Difference } \\
(\mathrm{K})\end{array}$ \\
\hline DC-8 & 18.7 & 273.462 & 270.964 & -2.498 \\
DC-8 & 21.0 & 276.502 & 271.476 & -5.026 \\
DC-8 & 37.0 & 253.042 & 255.317 & 2.275 \\
DC-8 & 92.0 & 207.967 & 215.746 & 7.779 \\
DC-8 & $183.3 \pm 2$ & 227.900 & 228.619 & 0.719 \\
DC-8 & $183.3 \pm 5$ & 212.767 & 210.011 & -2.756 \\
DC-8 & $183.3 \pm 9$ & 198.667 & 196.182 & -2.485 \\
\hline ER-2 & 10.7 & 225.720 & 223.330 & -2.390 \\
ER-2 & 19.35 & 278.940 & 271.05 .3 & -7.887 \\
ER-2 & 37.0 & 264.300 & 25.50 .5 & -11.795 \\
ER-2 & 89.0 & 203.460 & 193.787 & -9.673 \\
ER-2 & 1.50 .0 & 142.400 & 151.372 & 8.972 \\
ER-2 & $183.3 \pm 1$ & 168.720 & 168.568 & -0.152 \\
ER-2 & $183.3 \pm 3$ & 151.780 & 151.152 & -0.628 \\
ER-2 & $183.3 \pm 7$ & 140.220 & 1.22 .563 & 2.343 \\
ER-2 & 220.0 & 127.140 & 128.127 & 0.987 \\
\hline
\end{tabular}


Table 3: Convective Updraft $T_{B}$ Comparisons

\begin{tabular}{|c|c|c|c|c|}
\hline aircraft & $\begin{array}{c}\text { frequency } \\
(\mathrm{GHz})\end{array}$ & $\begin{array}{c}\text { TOG.A-COARE } \\
\text { Observations }\end{array}$ & $\begin{array}{c}T_{B} \\
\text { Calculations }\end{array}$ & $\begin{array}{c}\text { Difference } \\
(\mathrm{K})\end{array}$ \\
\hline DC-8 & 18.7 & 273.723 & 270.435 & -3.288 \\
DC-8 & 21.0 & 272.475 & 266.981 & -5.494 \\
DC-8 & 37.0 & 225.620 & 229.117 & 3.497 \\
DC-8 & 92.0 & 152.267 & 161.748 & 9.481 \\
DC-8 & $183.3 \pm 2$ & 218.467 & 215.267 & -3.200 \\
DC-8 & $183.3 \pm 5$ & 193.533 & 186.791 & -6.745 \\
DC-8 & $183.3 \pm 9$ & 170.167 & 171.180 & 1.013 \\
\hline ER-2 & 10.7 & 241.067 & 240.078 & -0.989 \\
ER-2 & 19.35 & 27.7 .500 & 268.833 & -6.667 \\
ER-2 & 37.0 & 243.700 & 224.610 & 19.090 \\
ER-2 & 89.0 & 159.767 & 152.650 & -7.117 \\
ER-2 & 150.0 & 137.233 & 142.277 & 5.044 \\
ER-2 & $183.3 \pm 1$ & 177.800 & 171.501 & -6.299 \\
ER-2 & $183.3 \pm 3$ & 159.333 & 153.520 & -5.813 \\
ER-2 & $183.3 \pm 7$ & 142.400 & 144.035 & 1.635 \\
ER-2 & 220.0 & 129.833 & 136.454 & 6.621 \\
\hline
\end{tabular}




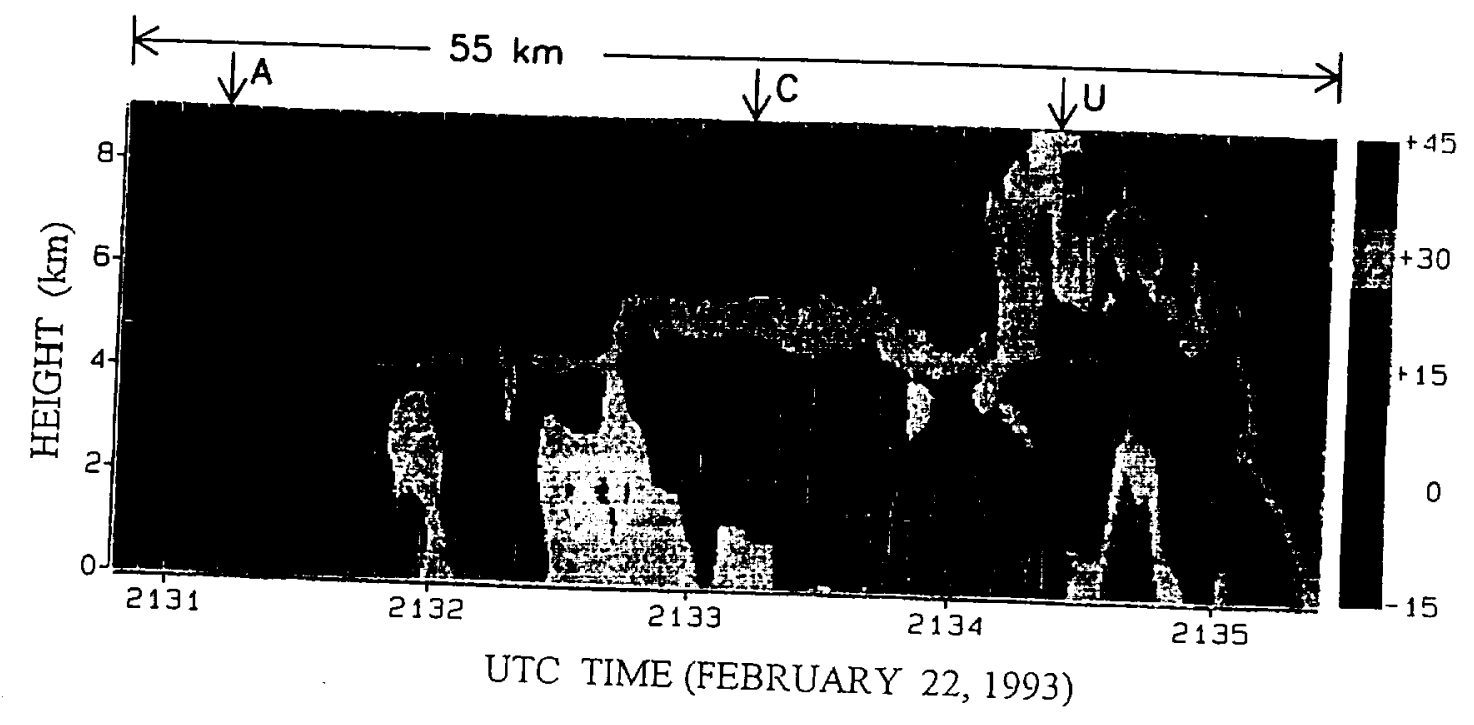

Figure 1

Skofronick-Jackson and Wong 

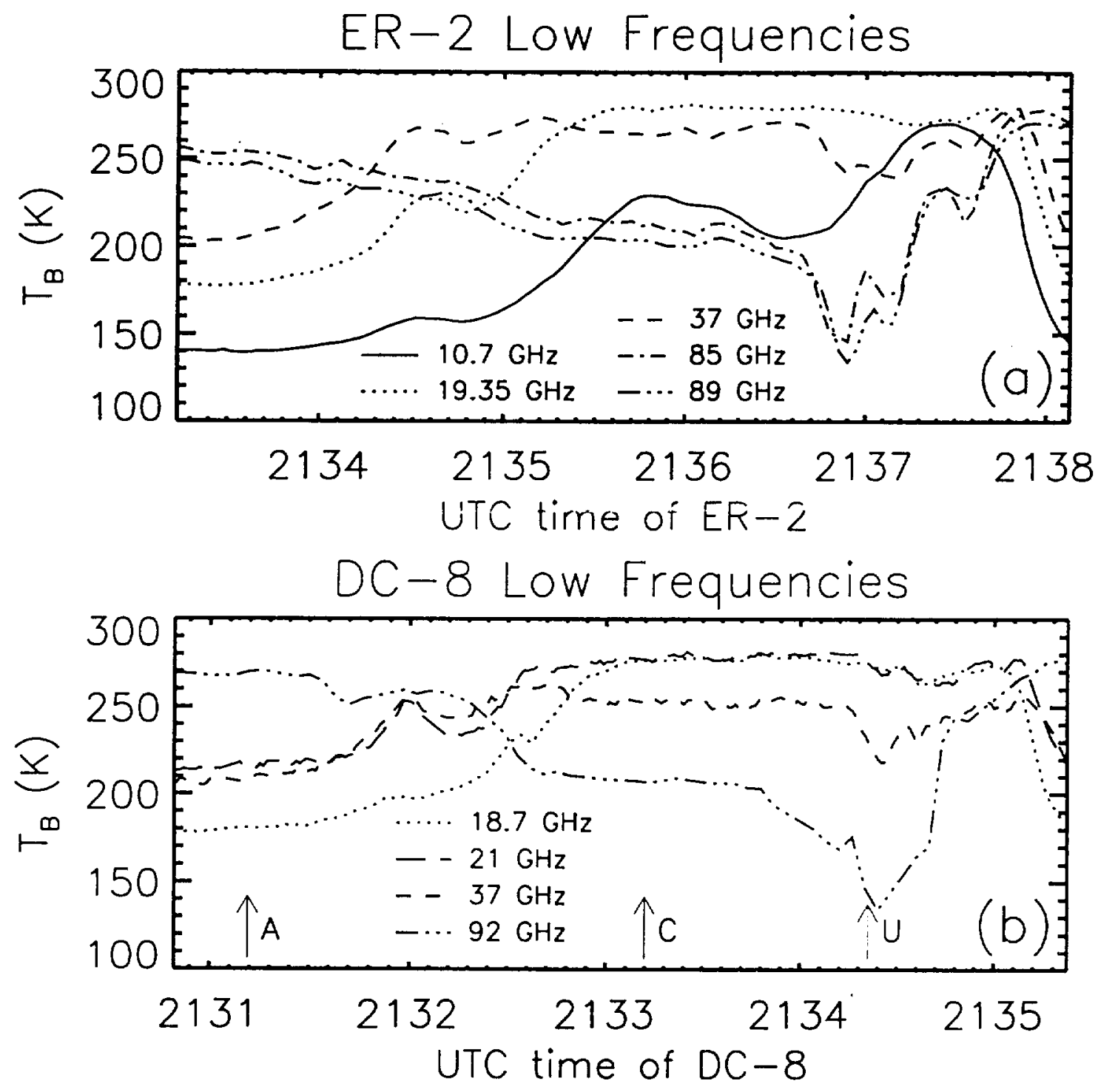

Figure 2

Skofronick-Jackson and Wang 

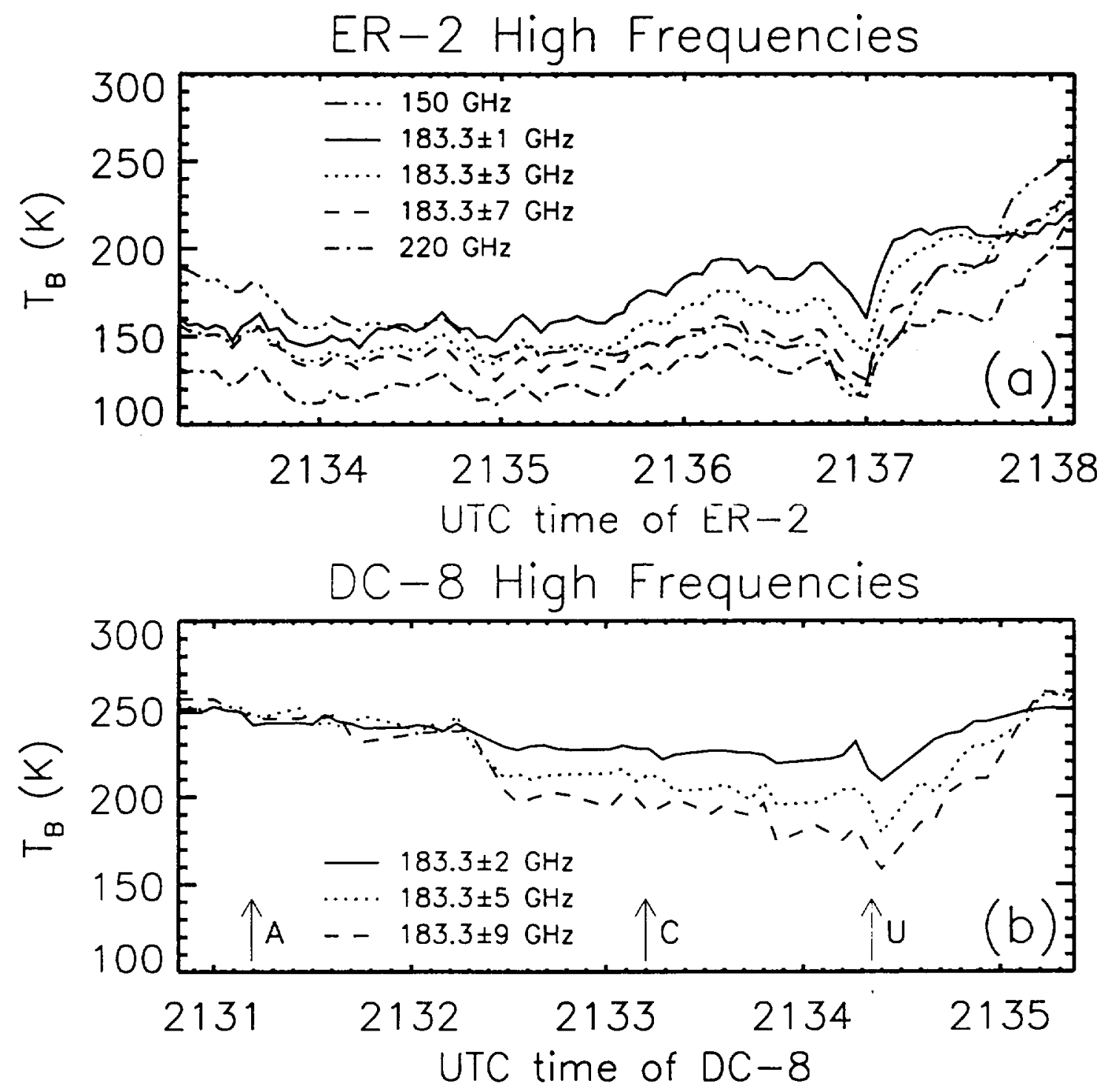

Figure 3

Skofronick-Jackson and Wang 

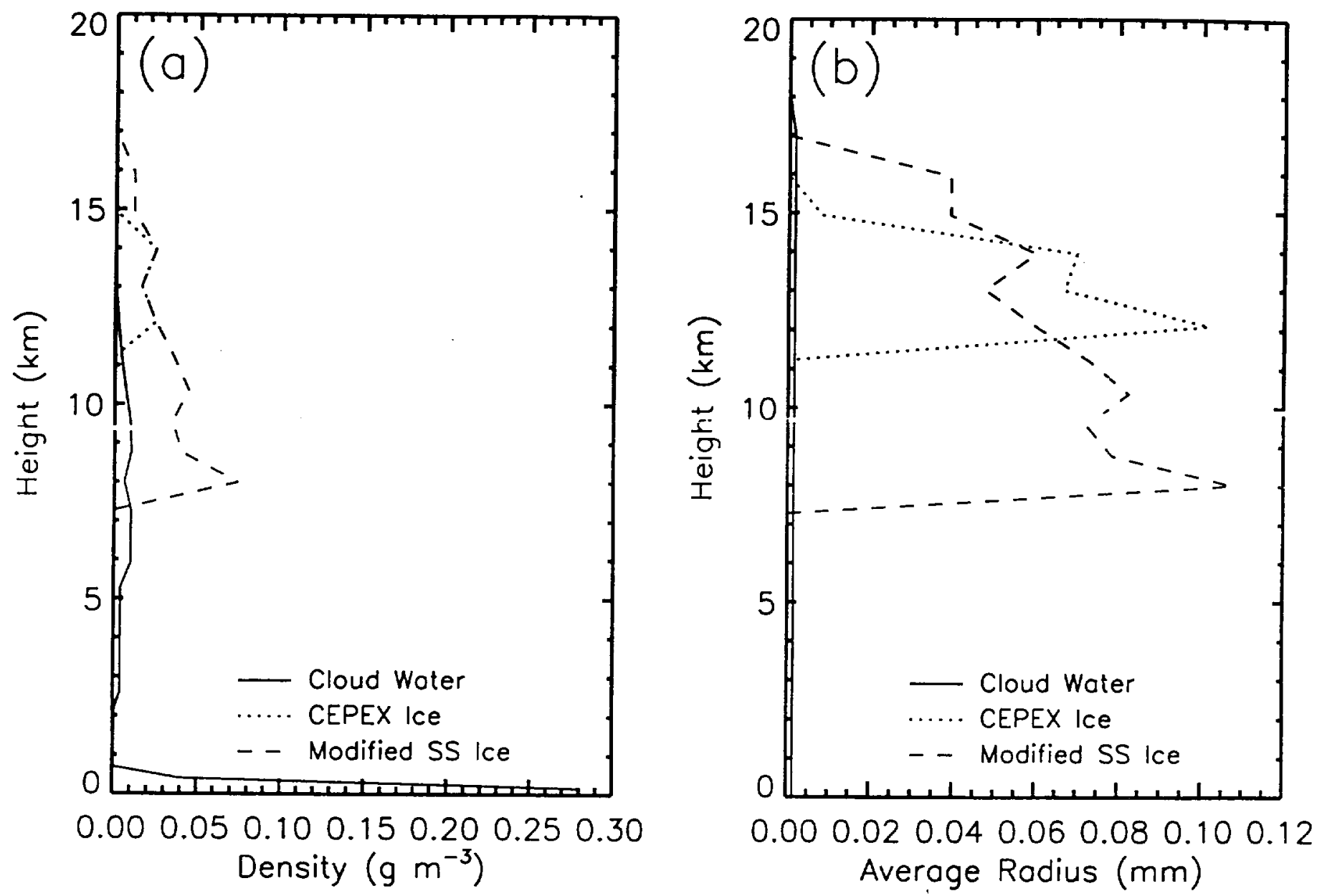

Figure 4

Skofronick-Jackson and Wang 

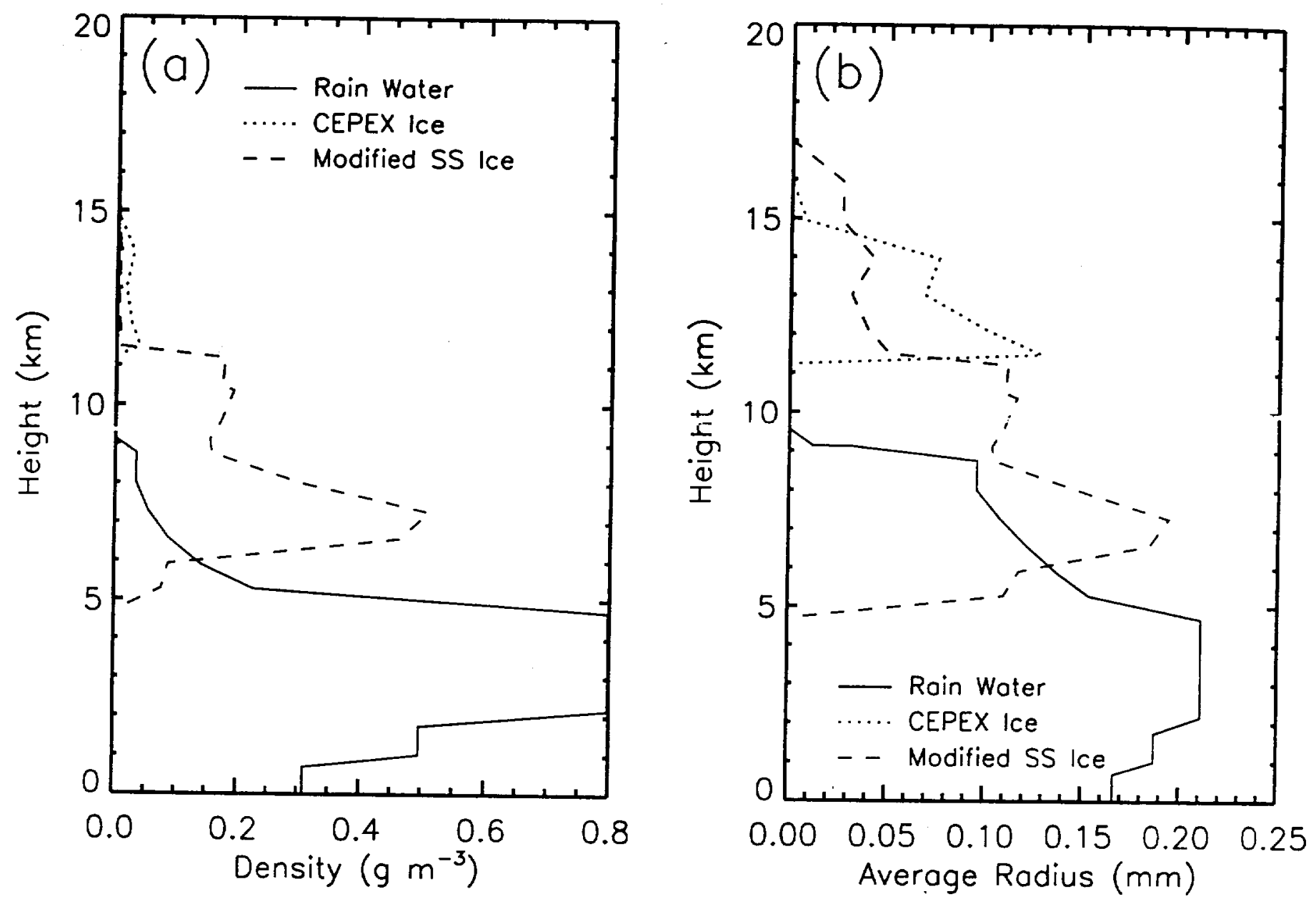

Figure 5

Skofronick-Jackson and Wong 

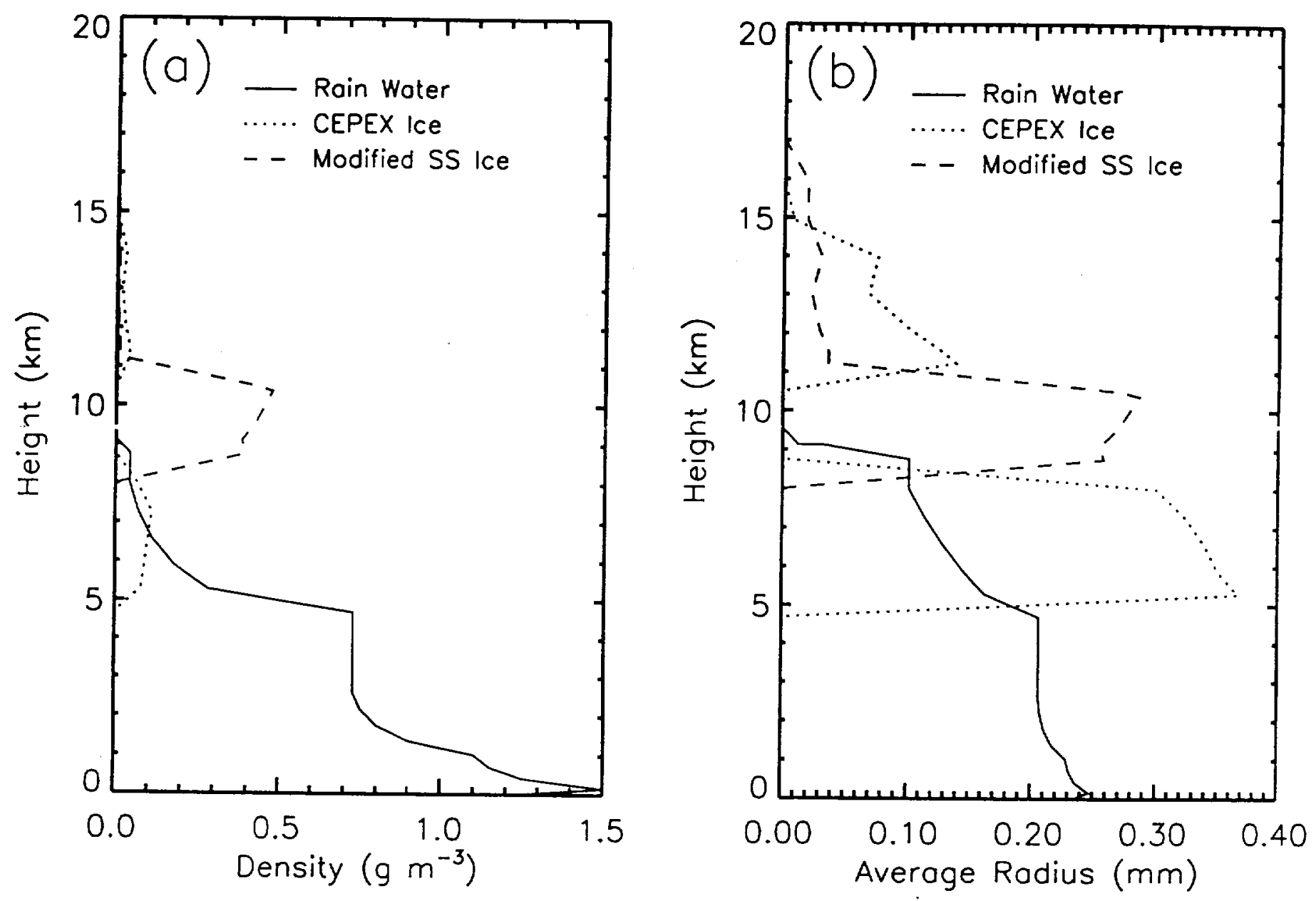

Figure 6

Skofronick-Jackson and Wong 